\title{
Cassava Processing Into "Attiéké” (A West Africa Fast Food): Wastewater Quantification and Pretreatment Using Two Fermentative Additives (Saccharomyces Cerevisiae and Sodium Bicarbonate)
}

Olga Y. A. Ako, Tenguel S. Nguessan, Tiama G.N. Ballet, Ossey B. Yapo, and Mamadou Koné

\section{ABSTRACT}

The need for alternative energy sources rises steeply researches on residual agricultural biomass. Artisanal processing of agricultural products in the agri-food chains represent an essential pollution source in most emerging countries and get interest also in the energy sector. The present study final objective enables to convert wastewater from cassava processing in Attiéké, a traditional food largely consumed in West Africa, to energy in a cheapest way. To achieve the purpose, cassava processing wastewater $\mathrm{pH}$ and biodegradability was improved to perform an anaerobic digestion. Hence, two common fermentive and cost effective additives were used. Yeast (organic compound) and Sodium bicarbonate (inorganic compound) effect were compared at different amounts mix with the same quantity of cassava wastewater. The experiments were carried out in triplicate. The best $\mathbf{p H}$ result was obtained from $7 \mathrm{~g}$ of Saccharomyces cerevisiae per liter of cassava wastewater which increased the $\mathrm{pH}$ from 3.83 to 4.57 . While $40 \mathrm{~g}$ Sodium bicarbonate per liter of cassava waster, increased the $\mathrm{pH}$ to maximum 4.17. In anaerobic environment after 15 days, Sodium bicarbonate addition (5g, $10 \mathrm{~g}, 20 \mathrm{~g}$ and $40 \mathrm{~g}$ ) increase the carbon fraction thus the mixture biodegradability but not gas production. The best additive was found to be Saccharomyces cerevisiae in comparison to Sodium bicarbonate. Results should help when to choose a cost effective additive for cassava wastewater pretreatment prior anaerobic co-digestion of cassava wastewater.

Keywords: Saccharomyces cerevisiae, Sodium bicarbonate, Fermentive Additive, Attiéké, Cassava wastewater quantification, Anaerobic pretreatment, Biodegradability.
Published Online: November 8,2020

ISSN: 2684-5199

DOI: 10.24018 /ejbio.2020.1.6.101

\section{O.Y. A. Ako*}

Nangui Abrogoua University, UFR-SGE (Environmental Sciences Laboratory) Abidjan, Côte D'ivoire.

(e-mail: kablancanyol.sge ${ }^{\circledR}$ univ-na.ci)

T. S. Nguessan

Nangui Abrogoua University, UFR-SGE (Environmental Sciences Laboratory)

Abidjan, Côte D'ivoire.

(e-mail: nguessans@yahoo.fr)

T. G. N. Ballet

Nangui Abrogoua University, UFR-SGE (Environmental Sciences Laboratory)

Abidjan, Côte D'ivoire.

(e-mail: tballet@yahoo.com)

O. B. Yapo

Nangui Abrogoua University, UFR-SGE (Environmental Sciences Laboratory)

Abidjan, Côte D'ivoire.

(e-mail: yapossey@yahoo.fr)

M. Koné

Nangui Abrogoua University, UFR-SGE (Environmental Sciences Laboratory)

Abidjan, Côte D'ivoire.

(e-mail: mamadou_ko@hotmail.com)

*Corresponding Author

\section{INTRODUCTION}

The artisanal processing of agricultural products is an essential element of the agri-food chains and its waste contribute for serious growing environmental issues. Hence initiatives are needed to produce alternative energy coupled with the valorization of these artisanal processing agricultural products wastes. Cassava (Manihot esculenta) is a vital crop to the economies of most emergent tropical countries, as a source of household cash income [1], easy to cultivate as it grows in almost all regions [2]. Africa annual Cassava production was estimated to $61,331,750$ tons in 2013 [3]. In Côte d'Ivoire, cassava ranks second in food crops after yam with an annual production of 4.2 million tons in 2014 [4]. Recently, a widely consumption of Attiéké (an artisanal fermented cassava product) was observed in Côte d'Ivoire and beyond the country boundaries because of its low cost and is a convenient fast food.

The process to obtain Attiéké from Cassava generates a large amount of residues with high pollution expectation due to its highest starch content within all tubercles. The anaerobic digestion potential of cassava crops and residues and various pretreatment comparison have been widely investigated [5]-[6]. Nonetheless, the need to improve financial sustainability of anaerobic digestion has raised attention until utilization of additives to stimulate microbial activity and/or reduce the inhibitory effect of various agents in a pretreatment [7], [8]. Considering cassava wastewater, no treatment prior anaerobic digestion using Saccharomyces cerevisiae and Sodium bicarbonate as additives has been yet done.

As the World faces environmental issues, the climate change mitigation in agro industrial sector become critical to reduce emissions and build resilience in food sector all using low cost materials.

Hence, through Attiéké production process, we focus in this paper, to first of all determine the exact amount of cassava wastewater by means of starch wastewater per quantity of produced Attiéké for a treatment plant sizing. Then monitoring the effect of two common fermentive 
organic and inorganic (yeast and Sodium bicarbonate) additives. As yeast already showed a cassava peels nutrient capacity improvement for animals' nutrition [9], expectation to optimize anaerobic digestion of cassava starch wastewater will be studied.

\section{MATERIAL AND METHODS}

Investigations were realized in Abidjan, Ivory Coast economical capital where Attiéké producers are concentrated and production reaches about 100 Tons per day [10].

\section{A. Survey}

\section{- Participants}

45 women who produce Attiéké in Yopougon, Attécoubé; Anoumanbo; Azito village; Abobodoumé; Abobo and Adjamé were submitted to a questionnaire, two times per week in the respect of Attiéké production frequency for one (1) month.

\section{- Survey design}

The questionnaire included a letter explaining the purpose of the study. The questionnaire consisted of three parts. In the first part, women's characteristics were collected. This included age, education, ethnicity, marital status. The second part of the questionnaire contained the detail of all steps releasing waste and quantification during Attiéké production and frequency in a week. The third part of the questionnaire were well understood by all the participants of the pilot study, and therefore, only minor modifications were made to the final version of the survey.

- Statistical analysis

The Statistical package for Social Science (S.P.S.S) software was used for data processing and analysis.

\section{B. Laboratory Experimental Activities}

\section{- Samples collection}

Wastewater from the various outlet productions' areas (Yopougon, Attécoubé; Anoumanbo; Azito village; Abobodoumé; Abobo; Adjamé) were collected and averaged for the study.

\section{- Technical material}

- 24 plastic sealed bottles of 1.5 L capacity each with $1 \mathrm{~L}$ working volume.

- A mechanical type suspended weighing scale $200 \mathrm{~g}$ precision was used to evaluate waste different amount with a bucket as waste container.

- A precision balance type BAXTRAN (Model ANG200 A1) was used to weigh additives (Saccharomyces cerevisiae and Sodium bicarbonate).

- $\mathrm{pH}$ and the Temperature parameters were measured using a multi parameter type HANNA Hi 9828.

- A spectrophotometer HACH DR 6000 was used for Chemical Oxygen Demand (COD).

- Total Nitrogen was measured using the HACH DRB200 thermostat.

- OxiTop ${ }^{\mathrm{TM}}$ measured the Biochemical Oxygen Demand in 5 days ( $\left.\mathrm{BOD}_{5}\right)$.

- Analysis procedure

$1 \mathrm{~L}$ of Cassava process wastewater (starch waste and wash water) was put in each plastic bottle. The organic additive Saccharomyces cerevisiae or inorganic additive Sodium bicarbonate were weighted and added to bottles at different amounts (Table I). Each test was done in triplicate, all were mixed well. One test by means of three bottles without additive served as control. $\mathrm{pH}$ and Temperature were instantly measured. Then all bottles were maintained in anaerobic environment at room temperature $\left(28.3 \pm 0.1^{\circ} \mathrm{C}\right)$ for more than 15 days.

Before and after incubation, parameters $\mathrm{BOD}_{5}, \mathrm{COD}$ in addition to $\mathrm{pH}$ and temperature were measured; then, $\mathrm{BOD}_{5}$ /COD ratio was used to see the biodegradability evolution.

\section{- COD Measurement}

COD was measured using a method of digestion in a TNT tube reactor then reading by bar code with the $\mathrm{HACH}$ DR 6000. The results in $\mathrm{mg} / \mathrm{L}$ COD are defined as the mass in $\mathrm{mg}$ of oxygen consumed per liter of sample under procedure conditions. In this procedure, the sample is warmed for two hours using potassium dichromate, a strong oxidizing agent. Oxidizable biological compounds react, reducing the dichromate ion $\left(\mathrm{Cr}_{2}^{-} \mathrm{O}_{7}{ }^{2-}\right)$ to the chromic ion $\left(\mathrm{Cr}_{3}{ }^{+}\right)$. Analysis results in the range 3 to $150 \mathrm{mg} / 1 \mathrm{COD}$ are obtained at $420 \mathrm{~nm}$. Analysis results in the range 20$1500 \mathrm{mg} / \mathrm{L}$ COD are obtained at $620 \mathrm{~nm}$

\section{- BOD5 Measurement}

The determination of $\mathrm{BOD}_{5}$ concentration was done with OxiTopTM system which is based on the principle of pressure. In the desired sample with quantity saturated with oxygen, a magnetic bar is added to the sample in a flask, then the rubber cup into the neck of the flask is inserted and two soda tablets were put in the rubber neck using pliers. Then the OxiTopTM is screwed directly onto the sample bottle and started the measurement. The measured bottle with the OxiTopTM is put at $20{ }^{\circ} \mathrm{C}$ for five days. As soon as the measuring temperature is reached, the OxiTopTM automatically starts the measurement of the oxygen consumption. The oxygen consumption results in a vacuum within the vial, a vacuum measured automatically by the OxiTopTM head at a frequency depending on the total duration of the test. Assuming that the oxygen consumed during the test is the cause of the pressure drop and that all of the $\mathrm{CO}_{2}$ produced is trapped by the soda. The vacuum measured is proportional to the volume of oxygen consumed which can be determined. The value is automatically memorized by the OxiTop every 24 hours over 5 days.

\section{- Nitrogen measurement}

The method used consists in assaying consecutively in a $20 \mathrm{~mm}$ dry reaction tube, $1.3 \mathrm{ml}$ of sample with Hach reagents addition $(1.3 \mathrm{ml}$ of solution $\mathrm{A}$ and 1 tablet of reagent $\mathrm{B})$. The reaction tube was close immediately without mix then is heated for one hour in the DRB 200 reactor. The test pieces are cooled to room temperature $\left(15-20^{\circ} \mathrm{C}\right)$. A Micro Cap $\mathrm{C}$ is added to the homogenized test tube until no particles remaining in the solution after pipetting $0.5 \mathrm{ml}$ of disaggregated sample from the reaction tube. The content is transferred to a cell of analysis then took $0.2 \mathrm{ml}$ of solution $\mathrm{D}$ into the analysis cuvette.

After waiting 15 minutes, wipe the outside of the bowl and place it in the bowl compartment. The spectrophotometer reads the barcode, then selects and performs the appropriate analysis 


\section{- Analytical process}

As test were done in triplicate, data were subsequently averaged; the deviations obtained were found to be less than $4 \%$.

TABLE I: PHySICO-CHEMICALS PARAMETERS VALUES IN Situ AFTER ADDITIVES (SODIUM BICARBONATE, SACCHAROMYCES CEREVISIAE) ADDITION BEFORE ANAEROBIC INCUBATION FOR MORE THAN 15 DAYS

\begin{tabular}{ccccccccc}
\hline \hline & & \multicolumn{4}{c}{ Sodium Bicarbonate $(\mathrm{g})$} & \multicolumn{4}{c}{$\begin{array}{c}\text { Saccharomyces } \\
\text { cerevisiae }(\mathrm{g})\end{array}$} \\
\hline Sample & Control & 5 & 10 & 20 & 40 & 7 & 14 & 21 \\
\hline $\mathrm{pH}$ & 3.83 & 3.84 & 3.84 & 3.86 & 4.17 & 4.57 & 6.23 & 7.30 \\
\hline $\mathrm{T}^{\circ} \mathrm{C}$ & 28.3 & 28.3 & 28.5 & 28.4 & 28.3 & 28.2 & 28.4 & 28.2 \\
\hline \hline
\end{tabular}

\section{RESULTS AND DISCUSSION}

From the survey, the study shows two varieties of cassava are used for Attiéké production (Yace and Yavo) and within all participants the main variety used is Yace variety for about $82.2 \%$ (Fig. 1). It is established that the Yace variety give better Attiéké quality [11]-[12]. The transformation rates of cassava into attiéké oscillate around $55.3 \%$ (Table II), or 0.55 kilogram Attieké for $1 \mathrm{~kg}$ of processed cassava. The study therefore reveals that on average $44.7 \%$ of cassava received is lost as waste (liquids and solids).

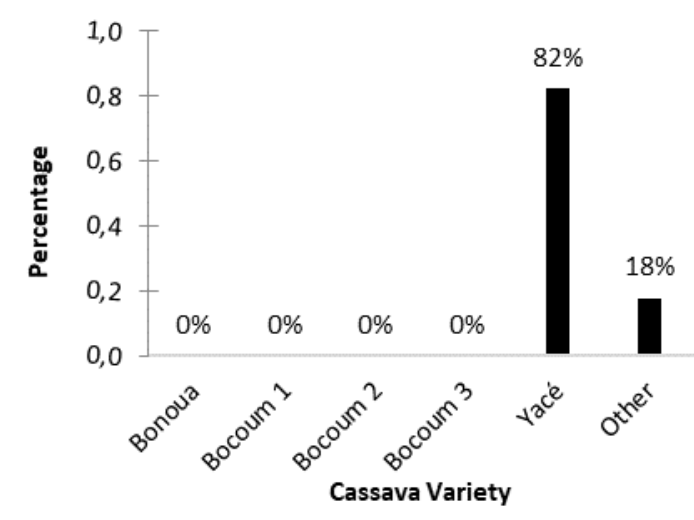

Fig. 1. Cassava used variety.

\section{A. Liquids Waste Production during Attiéké Process}

Liquid Waste which consist of starch waste and wash water, is measured and value summarize in Table II.

TABLE II: Cassava Process Data Per Producer Per Production

\begin{tabular}{lc}
\hline \multicolumn{2}{c}{ DAY } \\
\hline \hline Received Cassava $(\mathrm{kg})$ & 861.72 \\
\hline Peeled Cassava $(\mathrm{kg})$ & 613.10 \\
\hline Wash water $(\mathrm{L})$ & 88.99 \\
\hline Crushed and pressed Cassava $(\mathrm{kg})$ & 452.77 \\
\hline Pressed Juice $(\mathrm{L})$ & 212 \\
\hline Produced Attiéké $(\mathrm{kg})$ & 476.56 \\
\hline \hline
\end{tabular}

Hence, 1T processed Cassava produce about $349.3 \mathrm{~L}$ liquid waste by means of $0.35 \mathrm{~m}^{3}$ which is rejected in environment per Tons per producer per production day; results similar to [13].

\section{B. Effect of Sodium Bicarbonate and Saccharomyces Cerevisiae Addition on $\mathrm{pH}$}

Cassava liquid waste is acidic (3.83) and it is well known that acidic environment inhibit anaerobic digestion. The utilization of additives as presented in Table II shows Saccharomyces cerevisiae and Sodium bicarbonate effect on cassava wastewater samples. Until $40 \mathrm{~g}$ of Sodium bicarbonate addition, no significant effect on $\mathrm{pH}$ is observed nevertheless with Saccharomyces cerevisiae only $7 \mathrm{~g}$ was enough to increase the wastewater $\mathrm{pH}$ from 3.83 to 4.57. $14 \mathrm{~g}$ and $21 \mathrm{~g}$ change the $\mathrm{pH}$ to 6.23 and 7.30 , respectively. [14] has demonstrated the Saccharomyces cerevisiae well growth in acidic environment. Hence, a suitable environment for the bacteria growth induce a $\mathrm{pH}$ increase. In comparison to Sodium bicarbonate, Saccharomyces cerevisiae is better additive to increase cassava wastewater pH. Volatils Fatty Acids (VFA), an important anaerobic inhibiting parameter [15] could explain why the $40 \mathrm{~g}$ of Sodium bicarbonate addition had no effect on $\mathrm{pH}$ as it represents the main cause of medium acidification during anaerobic process. Unfortunately, VFA was not measure during the experiment.

\section{Biodegradability Comparison Before and After Incubation}

- Using Sodium bicarbonate as inorganic additive

$\mathrm{BOD}_{5} / \mathrm{COD}$ ratio is usually used to express the biodegradability of wastewater. Fig. 2 shows the biodegradability ratio.

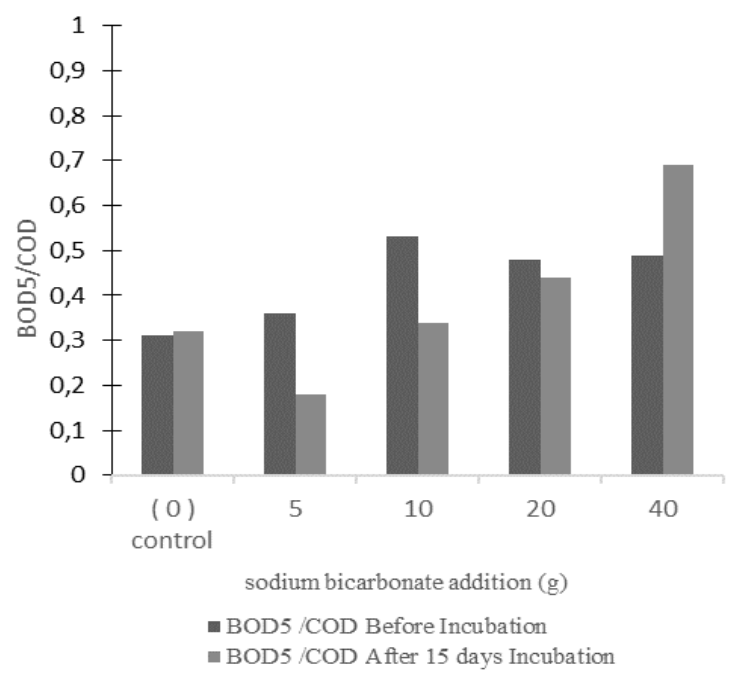

Fig. 2. Biodegradability measurement with Sodium bicarbonate as additive.

A ratio up to 0.4 attested that the wastewater is easily biodegraded [16]-[17]. Before anaerobic incubation, when Sodium bicarbonate amount added increase, the biodegradability ratio augment. In liquid environment, bicarbonate ions from Sodium bicarbonate, re equilibrated until an equilibrium is established. The main equilibria are:

$$
\begin{gathered}
\mathrm{HCO}_{3}{ }^{-} \rightarrow \mathrm{CO}_{3}{ }^{2-}+\mathrm{H}^{+} \mathrm{pKa}=10.33(1) \\
\mathrm{CO}_{2}+\mathrm{H}_{2} \mathrm{O} \rightarrow \mathrm{HCO}_{3}^{-}+\mathrm{H}^{+} \mathrm{pKa}=6.33(2)
\end{gathered}
$$


Carbonate is finally incorporated to the inorganic and organic carbon cycle [18]. Hence, Sodium bicarbonate directly increases the biodegradability considering before or after anaerobic incubation. After 15 days incubation almost, no gas was observed in the plastic bottles headspace.

- Saccharomyces cerevisiae as organic additive

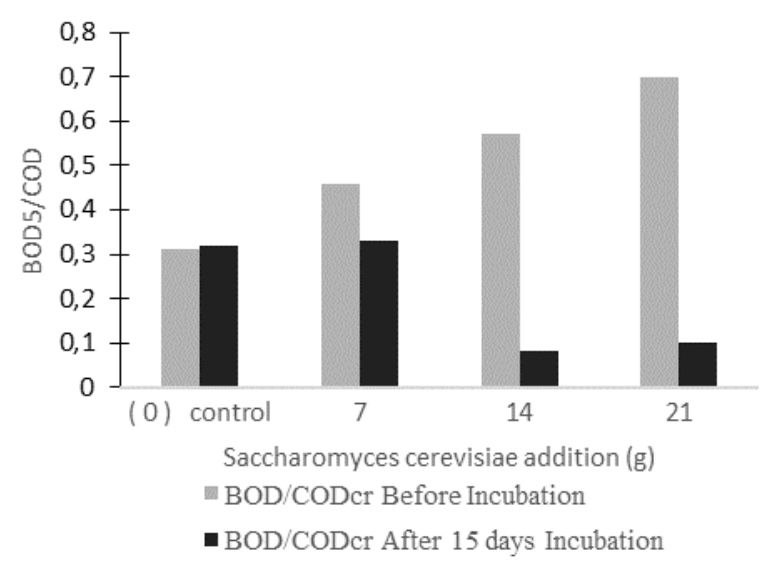

Fig. 3. Biodegradability measurement with Saccharomyces cerevisiae as organic additive.

As presented in Fig. 3, the biodegradability increase with the Saccharomyces cerevisiae addition this, before anaerobic incubation. When the mixture (yeast + wastewater) is maintained in anaerobic environment, the biodegradability decreases in all samples. Saccharomyces cerevisiae as organic additive decrease the biodegradability ratio in anaerobic environment when the control is compared after incubation to the samples with Saccharomyces cerevisiae addition. This could be an advantage for an anaerobic co-digestion.

\section{Total Nitrogen}

TABLE III: TOTAL NITROGEN AMOUNT AFTER ADDITIVES ADDITION

\begin{tabular}{ccccccccc}
\multicolumn{1}{c}{ TABLE III: TOTAL NITROGEN AMOUNT AFTER ADDITIVES ADDITION } \\
\hline \hline & \multicolumn{3}{c}{ Sodium Bicarbonate $(\mathrm{g})$} & \multicolumn{4}{c}{$\begin{array}{c}\text { Saccharomyces } \\
\text { cerevisiae }(\mathrm{g})\end{array}$} \\
\hline Sample & Control & 5 & 10 & 20 & 40 & 7 & 14 & 21 \\
\hline $\mathrm{pH}$ & 3.83 & 3.84 & 3.84 & 3.86 & 4.17 & 4.57 & 6.23 & 7.30 \\
\hline $\begin{array}{c}\text { Total } \\
\text { Nitrogen } \\
(\mathrm{mg} / \mathrm{L})\end{array}$ & 40 & 3 & 23 & 32 & 4 & 25 & 126 & 165 \\
\hline \hline
\end{tabular}

In Table III, the total nitrogen was found to be high at an increase in Saccharomyces cerevisiae quantity, this in comparison to the control total nitrogen. Cassava wastewater is known to be poor in nitrogen and Saccharomyces cerevisiae can be considered as the best additive.

\section{CONCLUSION}

Cassava processing wastewater is an important pollution source produced in West Africa. It represents $0.35 \mathrm{~m}^{3}$ per Tons of proceeded Cassava. The wastewater is generally rejected in the environment (soil or water pond) without any treatment. The use of additives in anaerobic digestion system has become a tremendous topic due to their capacity to improve reactors performances The realized study pretreated the wastewater to increase $\mathrm{pH}$; Saccharomyces cerevisiae was found to be the best additive to increase the $\mathrm{pH}$. Only $7 \mathrm{~g}$ of the fermentive additive per liter of Cassava waste was enough to increase the $\mathrm{pH}$. Anaerobic fermentation at mesophilic temperature with each additive confirmed the choice of Saccharomyces cerevisiae. The results could help to sizing anaerobic facilities and low-cost $\mathrm{pH}$ adjustment before anaerobic co digestion.

\section{REFERENCES}

[1] S. Dunstan, and E. Chuma, "Cassava cultivation in sub-Saharan Africa" in Hershey, C. (Ed.). Achieving sustainable cultivation of cassava. vol 1. London: Burleigh Dodds Science Publishing, 2017. https://doi.org/10.4324/9781351114264.

[2] A. Jarvis, J. Ramirez-Villegas, H. Campo, V. Beatriz, and C. Navarro-Racines, "Is Cassava the Answer to African Climate Change Adaptation?" Tropical Plant Biol. vol. 5, pp. 9-29, 2012. https://doi.org/10.1007/s12042-012-9096-7.

[3] FAO, FAOSTAT, 2013. http://faostat.fao.org/site/339/default.aspx8.

[4] FAO, «Perspectives de l'alimentation: rapport semestriel sur les marchés alimentaires mondiaux. Rapport semestriel, Rome, 41p., 2017 http://www.fao.org/3/a-I8080e.pdf.

[5] V. Okudoh, C. Trois, and T. Workneh, "The Potential of Cassava Biomass as a Feedstock for Sustainable Biogas Production in South Africa" Journal of Energy and Power Engineering, vol 8 pp. 836843, 2014.

[6] A. Pandey, C. R. Soccol, P. Nigam, D. Brand, R. Mohan, and S. Roussos, "Biotechnological potential of coffee pulp and coffee husk for bioprocesses". Biochemical Engineering Journal, vol 6, no.2, pp. 153-162, 2000.

[7] M. Carlsson, A. Lagerkvist, F. Morgan-Sagastume, "The effects of substrate pretreatment on anaerobic digestion systems: a review". Waste Management, vol 32, pp. 1634-50, 2012.

[8] H. Carrère, C. Dumas, A. Battimelli, DJ. Batstone, JP. Delgenès, JP. Steyer et al., "Pretreatment methods to improve sludge anaerobic degradability: a review", Journal of Hazardous Materials, vol 183, pp.1-15, 2010.

[9] G. Oboh, "Nutrient enrichment of cassava peels using a mixed culture of Saccharomyces cerevisiae and Lactobacillus spp. solid media fermentation". Electronic Journal of Biotechnology, vol 9 no. 1, pp. 46-49. 2006.

[10] N. T. Djeni, « Typologie de l'attiéké de trois zones de production de Côte d'Ivoire et analyse des propriétés des levains traditionnels utilisés pour sa préparation ». Thèse unique de Doctorat, Université Abobo-Adjamé. 2009.

[11] B. N'zué, G. P. Zohouri, C. Djédji, and O. Tahou, "Bien cultiver le manioc en Côte d'Ivoire ». Fiche technique, 4p. 2013 http://lorbouor.org/agrituto/manioc.pdf.

[12] Anader, 2017- Fiche technico-économique du manioc. http://www.anader.ci/fichetech/fiche\%20technicoeconomique\%20du\%20manioc.pdf.

[13] Kpata-Konan N. E., Konan K. F., Kouame Y. F., Gnagne Theophile \& Tano K. "Characterization of Waste from Attiéké Factory: Case of Azito Village (Abidjan, Côte d'Ivoire)". European Scientific Journal, vol 12, no. 35, 2016. ISSN: 1857 - 7881 (Print) e - ISSN 1857- 7431-73.

[14] J. Ariño, "Integrative responses to high $\mathrm{pH}$ stress in S. cerevisiae," OMICS A Journal of Integrative Biology, vol. 14, no. 5, pp. 517-523, 2010.

[15] M. Tcha-Thom, "Recherche d'une filière durable pour la méthanisation des déchets de fruits et d'abattoirs du Togo: Evaluation du potentiel agronomique des digestats sur les sols de la région de la Kara". Géochimie. Université de Limoges; Université de Lomé (Togo), 2019.

[16] R. A. Torres, V. Sarria, W. Torres, P. Peringer, and C. Pulgarin, "Sonolysis of natural phenolic compounds in aqueous solutions: degradation pathways and biodegradability", Water Research, vol. 37, pp. 3118-3124, 2003.

[17] M. Almutairi, "Method development for evaluating the effectiveness of hydrocarbons on BOD, UBOD and COD removal in oily wastewater". Water Science and Technology, vol. 81, no.12, 26502663, 2020.

[18] United Nations Environment Program (UNEP). "Sodium Bicarbonate" (PDF). Archived from the original (PDF) on 2011-05- 
European Journal of Biology and Biotechnology www.ejbio.org

16. SIDS Initial Assessment Report for SIAM 15 (Boston, USA, 22

$25 \quad$ October 2002).

http://www.chem.unep.ch/irptc/sids/oecdsids/Sodium

bicarbonate.pdf.

Dr. Olga Y. A. Ako, a PhD Holder in Biotechnology option Biomass Bioenergy from Tsukuba University in Ibaraki Prefecture of Japan. She was born in 1970 at Cocody Abidjan City of Côte d'Ivoire. She has interest in environmental biotechnological research. She is currently Associate Professor at Nangui Abrogoua University in Côte d'Ivoire and teaches undergraduate courses in the department of Environmental Sciences and Management.

Dr Tenguel S. Nguessan is a PhD Holder in Socio-Anthropologist and Health Economist $\mathrm{He}$ is with $\mathrm{Dr}$ Ako belong to the Environmental Sciences Laboratory at Nangui Abrogoua University.

Dr Tiama G. N. Ballet is PhD. Holder in Analytic Chemistry from the Environmental Sciences Laboratory.

Prof. Ossey B. Yapo, Executive Director, Ivorian Antipollution Centre (CIAPOL) Central Laboratory of Environment.

Prof Mamadou Koné is the Head of the Environmental Sciences Laboratory from Nangui Abrogoua University. 